\author{
대도시의 주거/도로변 지역 및 배경 지역의 대기 중 \\ 입자상 다환 방향족 탄화수소의 특성 \\ 장종대· 신승호 · 조완근 \\ 경북대학교 환경공학과 \\ (2010년 3월 16일 접수; 2010년 4월 23일 수정; 2010년 5월 20일 채택)
}

\title{
Characteristics of Particulate Atmospheric Polycyclic Aromatic Hydrocarbons Pollution in Residential/Roadside Areas of Metropolitan Cities and a Background Area
}

\author{
Jong-Dae Jang, Seung-Ho Shin, Wan-Kuen Jo* \\ Department of Environmental Engineering, Kyungpook National University, Daegu 702-701, Korea \\ (Manuscript received 16 March, 2010; revised 23 April, 2010; accepted 20 May, 2010)
}

\begin{abstract}
The present study aims to evaluate the characteristics of atmospheric polycyclic aromatic hydrocarbons (PAHs) pollution in roadside and residential areas of two Korean metropolitan cities (Seoul and Incheon) and a background area (Seokmolee). This purpose was established by analyzing temporal and spacial concentration distribution of total and 7 individual PAHs, which were extracted from ambient particulate matters, and by utilizing a multivariate statistical method (principal component analysis, PCA) for the qualitative determination of potential PAH sources. Target PAHs included benzo $(a)$ anthracene $(\mathrm{BaA})$, benzo $(\mathrm{a})$ pyrene $(\mathrm{BaP})$, benzo $(b)$ fluoranthene $(\mathrm{BbF})$, benzo $(k)$ fluoranthene $(\mathrm{BkF})$, chrysene $(\mathrm{Chr})$, dibenzo $(a, h)$ anthracene $(\mathrm{DahA})$, and indeno(1,2,3-cd)pyrene (IcdP). For all surveyed sites, the concentrations of total PAHs were higher in winter season than in other seasons. However, the concentrations of individual PAHs varied with surveyed sites. In both residential and roadside sites of Seoul and Incheon, BbF revealed the highest atmospheric levels. For all 7 target PAHs, the ambient concentrations were higher in Seoul and Incheon than in a background area (Seokmolee). In both residential and roadside areas, the concentrations of 4 target PAHs (BaA, BbF, BkF, DahA) were higher in Incheon than in Seoul. However, both the residential and roadside Chr concentrations were comparable in Seoul and Incheon. In addition, the residential IcdP concentrations were higher in Incheon than in Seoul, whereas the roadside concentrations were higher in Seoul. The roadside and residential BaP concentrations exhibited the reverse result to the IcdP concentrations. An PCA analysis suggested that atmospheric PAHs in both residential and roadside areas would be due to combined effects of several potential sources such as gasoline- and diesel-fueled vehicles, coal/oil combustion, and waste incineration.
\end{abstract}

Key Words : Spatial characteristic, Particulates, Individual PAHs, PAH source, Atmospheric level

\section{1. 서 론}

${ }^{*}$ Corresponding Author : Wan-Kuen Jo, Department of Environmental Engineering, Kyungpook National University, Daegu 702-701, Korea

Phone: +82-53-950-6584

E-mail: wkjo@knu.ac.kr
다환 방향족 탄화수소(polycyclic aromatic hydrocarbons, PAHs)는 두 개 또는 그 이상의 벤젠 고리를 포함하는 융합 고리 구조를 갖는 잔류성 유기 오염물 질로 분류된다(Vione 등, 2004). 이러한 PAHs는 다양 
한 환경에서 빈번하게 검출되고 독성이 강한 것으로 알려졌기 때문에 이에 대한 환경 노출로 인해 야기되 는 건강 위해성이 최근 많은 관심을 받고 있다(Mastral 등, 2003; USEPA, 2003; Esen 등, 2008). 도시 대기 중의 PAHs는 주로 디젤 및 가솔린 자동 연료 연소, 주 거지역 난방 연료 연소, 에너지 및 산업용 화석연료 연 소, 폐기물 소각과 같은 인위적인 오염원에서 배출된 다(Zielinska 등, 2004; Simoneit 등, 2005; Bi 등, 2008). 배출된 PAHs는 증기압에 따라 대기 중에서 가 스 형태 또는 입자 형태로 존재하지만, 가스상 PAHs 는 응결과정과 주변 입자에 흡착됨으로서 대기 중에 서는 주로 입자상 PAHs로 측정된다(Halsall 등, 2001). 결과적으로, 많은 종류의 입자상 PAHs가 국내 및 국외의 여러 도시 대기에서 빈번하게 측정되는 것 으로 보고되었다(이 등, 2008; 김 등, 2006; 한 등, 2006; Bruno 등, 2002; Amodio 등, 2008; Andreou와 Rapsomanikis, 2009). 특히, 도시 대기 환경에서 측정 된 수백 가지의 PAHs 중에서도 측정 빈도와 독성에 기초하여 16 가지의 $\mathrm{PAHs}$ 가 미국 환경보호국 (USEPA, 2003)에 의하여 우선관리 대상물질로 분류 되고 있다. 이들 중 일부 PAHs는 발암성과 돌연변이 성도 유발시키는 것으로 보고되었다(Kameda 등, 2005).

이러한 PAHs의 환경보건적 중요성 때문에, 도시인 들의 인체 위해성을 줄이기 위한 도시 대기 중 PAHs 관리방안 수립이 요구된다. 나아가, 도시 PAHs 관리 방안을 수립하기 위해서 우선적으로 대기 중 $\mathrm{PAHs}$ 의 거동 특성에 대하여 장기적이고 다양한 지형 용도에 따른 분류적 연구가 요구된다(Garban 등, 2002; Chang 등, 2006; Andreou와 Rapsomanikis, 2009). 이 러한 연구 필요성에 부응하기 위하여 본 연구는 국내 주요 도시의 공간적 및 시간적 $\mathrm{PAHs}$ 오염도에 대한 특성을 평가하고자 한다. 공간적으로는 서울시 및 인 천시를 선정하여 각 도시를 주거지역과 도로변 지역 으로 구분하고, 국내 배경지역들 중 인천시에 가장 근 접한 배경지역인 인천 석모리를 선정하여 대기 중 PAHs 농도 특성을 비교적으로 평가하였다. 시간적으 로는 PAHs 측정 자료의 검증 프로그램이 가동되고 자료의 질 신뢰도가 높은 2006년 이후의 PAHs 측정 농도만을 평가하였다. 본 연구는 대기 가스 및 입자성
PAHs 중 인체 위해도가 높은 대기 중 입자 형태 $\mathrm{PAHs}$ 의 시간적 및 공간적 농도 특성 분석에 초점을 맞추었고, 자료 확보의 한계성 때문에 PAHs 농도 특 성에 대한 원인 규명은 본 연구 범위에서 제외하였다. 나아가, PAHs의 도시 발생원에 대한 정보는 도시 대 기 중 PAHs를 저감시키는 전략에 이용될 수 있기 때 문에(Liu 등, 2007; Ravindra 등, 2008), 본 연구는 입 자상 $\mathrm{PAHs}$ 측정 농도 자료에 대하여 주성분 분석법 (principal component analysis, PCA)을 적용하여 대 상 지역들의 대기 중 PAHs 발생원에 대하여 정성적 으로 조사하였다. PCA 분석법은 다변량 통계적 분석 법으로서 선행연구에서 이 분석법이 대기 중 PAHs의 발생원을 정성적으로 평가하는데 성공적으로 응용된 적이 있다(Li 등, 2006; Ravindra 등, $2006 \mathrm{Liu}$ 등, 2007).

\section{2. 자료 및 방법}

\section{1. 연구 고안 및 측정 자료}

본 연구는 서울시의 주거지역인 도곡동과 도로변 지역인 서울역, 인천시의 주거지역인 숭의동과 도로 변 지역인 연희동, 그리고 배경지역인 석모리에서 2006년 1월 1일 부터 2008년 12월 31일까지 측정된 3 년 동안의 PAHs 월별 농도를 분석하였다. 연구 내용 은 PAHs의 시간적 및 공간적 특성을 평가하기 위한 각 도시의 측정 지점별 월간 총 $\mathrm{PAHs}$ 의 평균농도 특 성 조사, 계절별 개인 PAHs의 평균농도 특성 및 연간 총 PAHs 평균 농도 특성 조사, 3 년 동안 총 PAHs 평 균 농도에 대한 측정 지점의 비교 분석, 개인 PAHs 평 균 농도에 대한 지형 특성 비교 분석을 포함하며, 나아 가 PAHs의 오염원을 정성적으로 조사하기 위하여 주 거 지역과 도로변 지역 각각에 대하여 $\mathrm{PCA}$ 분석을 수 행한다. 분석에 이용되는 PAHs 측정 농도 자료는 대 기오염 측정망 설치운영지침에 근거하여 환경부에서 인구 50 만 이상의 도시지역, 주요 산업단지, 배경농도 지역에 설치하여 운영되는 유해 대기오염물질 측정망 자료이다. 조사 대상 PAHs는 다음과 같은 7 가지이며, 이들은 모두 $\mathrm{EPA}$ 의 우선관리대상물질에 해당한다: benzo( $a$ )anthracene(BaA, 4-ring) benzo(a)pyrene (BaP, 5-ring); benzo(b)fluoranthene(BbF，5-ring); 
benzo $(k)$ fluoranthene(BkF, 5-ring); chrysene(Chr, 4ring); dibenzo( $a, h)$ anthracene(DahA, 5-ring); 그리고 indeno(1,2,3-cd)pyrene(IcdP, 6-ring). PAHs 측정은 각 측정소를 관할하고 있는 유역(지방)환경청에서 수 행하며, 본 연구에서는 매월 24 시간동안 채취한 후에 미지피크에 대해 정확한 판독방법을 제공할 수 있는 $\mathrm{GC}-\mathrm{MSD}$ 를 이용하여 분석된 PAHs 자료가 활용되었 다.

\subsection{PCA}

서울, 인천 및 배경지역인 석모리의 대기 중 PAHs 에 대한 발생원을 추정하기 위하여 PCA가 이용되었 다. $\mathrm{PCA}$ 는 여러 개의 변수에 대하여 얻어진 다변량 자료를 분석의 대상으로 하여 다차원적인 변수들을 축소, 요약하는 차원의 단순화와 더불어 일반적으로 서로 상관되어 있는 변수들 상호간의 복잡한 구조를 분석하는 데 그 목적을 두고 있으며 원래의 변수들이 가진 전체변동에 대한 추출된 각 주성분의 공헌도를 순차적으로 최대화하도록 선택된 주성분을 도출 하도록 한다(Guo 등, 2004, 2007). PCA와 같은 다 변량 수용모델들은 내재적이거나 실질적으로 자료의 주성분 분석으로부터 시작되며 이러한 주성분들은 통 상 어떤 특정적인 방법으로 자료를 변환시킨다. PCA 모델은 이러한 주성분을 변환시키고 일단 변환된 주 성분들은 인자(Factor)로 불리운다. PCA는 다음과 같 이 표현된다:

$$
\mathrm{C}=\mathrm{UDV}^{\mathrm{T}}
$$

이 표현식에서 $\mathrm{C}$ 는 $\mathrm{m}$ (변수) $\times \mathrm{n}$ (자료수)개 자료의 행렬이고, $\mathrm{V}$ 는 $\mathrm{C}^{\mathrm{T}} \mathrm{C}$ 에 대한 $\mathrm{n} \times \mathrm{n}$ 개, $\mathrm{U}$ 는 $\mathrm{CC}^{\mathrm{T}}$ 에 대한 $\mathrm{m} \times \mathrm{m}$ 개의 고유벡터를 각각 의미하며, $\mathrm{D}$ 는 단일치 (singular values)를 이루기 위한 $\mathrm{m} \times \mathrm{n}$ 의 대각행렬 즉, 고유치에 상응하는 평방근을 의미하게 된다. 여러 가 지 수학적인 특성들은 유용하게 이용되는데 $\mathrm{C}^{\mathrm{T}} \mathrm{C}$ 와 $\mathrm{CC}^{\mathrm{T}}$ 의 고유치들은 항상 같으며, 행렬 $\mathrm{U}$ 와 $\mathrm{V}$ 는 직각 을 이루게 된다는 것이다.

$\mathrm{PCA}$ 에서 주성분은 자료행렬의 SVD로부터 얻어 질 수 있으며 식 (1)에서 $\mathrm{L}=\mathrm{UD}$ 및 $\mathrm{F}=\mathrm{V}^{\mathrm{t}}$ 로 두면 식 (2) 와 같이 된다.

$$
\mathrm{C}=\mathrm{L} \mathrm{F}
$$

PCA에서 L은 성분적재(component loadings) 행렬 로 불리며, $\mathrm{F}$ 는 성분점수(component scores)의 행렬 이 된다. 또한 이 식에서는 $\mathrm{L}=\mathrm{U}, \mathrm{F}=\mathrm{DV}^{\mathrm{T}}$ 로 놓을 수 있다. 이러한 방법을 Q-mode 분석이라 하며 전자와 같은 방법을 R-mode 분석으로 알려져 있다. 본 연구 에서는 R-mode가 이용된다. PCA의 주요 목적은 서 로 상관성을 가진 변수들을 가지는 자료에서 차원을 축소하여 최소의 인자를 가지고도 서로 상관성을 갖 는 자료에서 최대변동을 설명할 수 있도록 하는 것이 다. 분석에서 추출된 주성분들 중 첫째의 성분은 자료 가 갖는 전체변동 중 가장 많은 부분을 설명하게 되고, 둘째의 주성분은 첫째의 주성분에서 이미 설명하지 않고 잔존하는 변동을 최대한 설명하게 되며 이렇게 차기의 주성분들도 전개된다, 서로 상관성을 갖는 자 료에서 서로 상관이 없는 새로운 변수들의 세트로 직 교변환을 통해서 주성분을 분석한다.

\section{3. 결과 및 고찰}

\subsection{PAHs 농도의 시간적 및 공간적 특성}

Fig. 1-3는 각각 서울시, 인천시 및 배경지역인 석 모리에서 측정된 월간 총 $\mathrm{PAHs}$ 의 평균 농도 변화를 나타낸다. 서울시의 경우, 도로변과 주거 지역 모두에 서, 하절기에 비해 동절기에 총 PAHs 농도가 높게 나 타났다. 이러한 경향은 동절기에 난방 연료가 많이 소 요되거나 낮은 대기 온도로 인한 불완전 연소가 많기 때문인 것으로 해석된다(Vione 등, 2004; Zielinska 등, 2004; Simoneit 등, 2005). 일년 중 동절기가 2 개 월 포함된 6 개월 동안은 $(5,8,9,10,11$, 및 12 월 $)$ 주거 지역에 비해 도로변 지역의 총 PAHs 농도가 높게 나 타났고, 그 외 6개월 동안은 이와 반대의 결과가 나타 났다. 주거 지역에서 상대적으로 높은 PAHs 농도가 측정된 달에는 주거 지역의 난방연료 또는 취사시 연 료 사용으로 인한 대기 PAHs 농도 기여도가 도로변 의 차량에서 배출되는 PAHs 농도 기여도보다 큰 것 을 의미한다(Vione 등, 2004). 그러나, 난방연료가 많 이 소모되는 동절기에 포함되는 1 월에는 오히려 난방 연료 또는 취사 연료 사용으로 인한 대기 PAHs 농도 


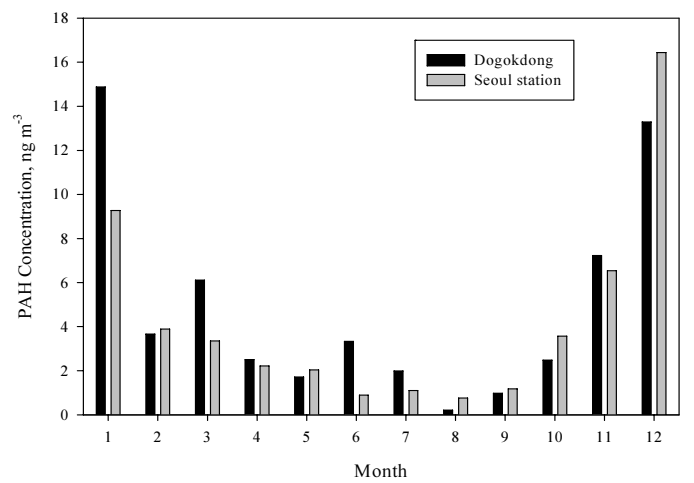

Fig. 1. Monthly variation of total $\mathrm{PAH}$ concentrations in Seoul, between January 1, 2006 and December, 31, 2008: Dogokdong (residential site) and Seoul station (roadside site).

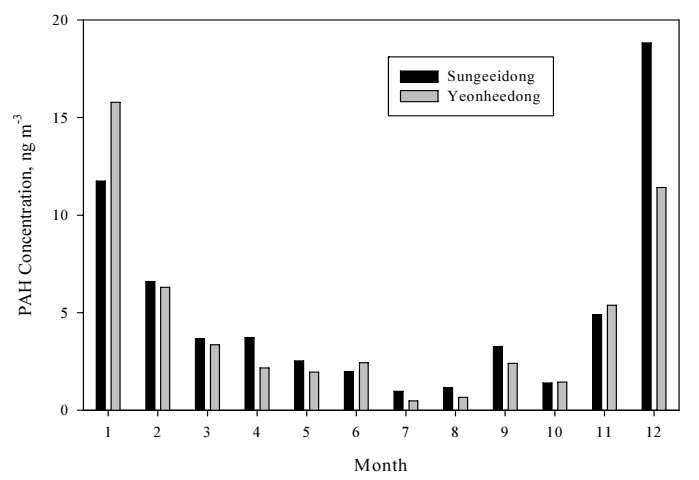

Fig. 2. Monthly variation of total PAH concentrations in Incheon, between January 1, 2006 and December, 31, 2008: Sungeeidong (residential site) and Yeonheedong (roadside site).

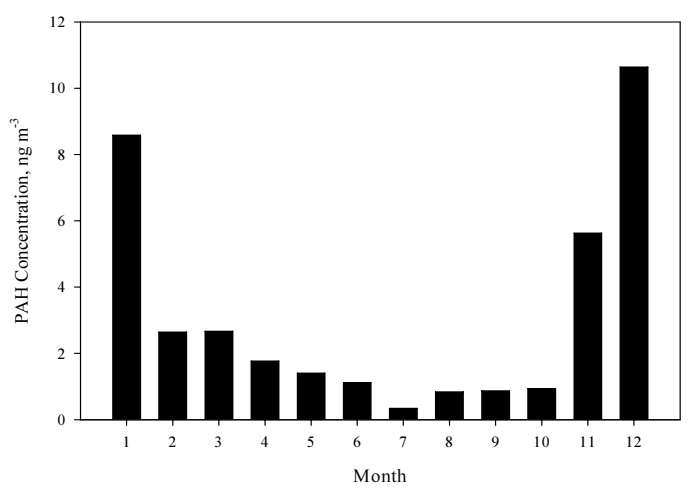

Fig. 3. Monthly variation of total PAH concentrations in a background area (Seokmolee), between January 1, 2006 and December, 31, 2008.
기여도보다 도로변의 차량에서 배출되는 PAHs 농도 기여도가 더 큰 것으로 나타났다.

인천시와 배경지역인 석모리의 경우에도, 서울시 와 유사하게, 도로변과 주거지역 모두에서, 하절기에 비해 동절기에 총 PAHs 농도가 높게 나타났다(Fig. 2,3). 그러나, 시간적으로는, 동절기 중 2 개월(1월과 11 월) 그리고 하절기 1개월(6월)을 제외하고는 나머 지 9 개월 동안에 도로변 지역에 비해 주거 지역에서 총 PAHs 농도가 높게 나타났다. 종합적으로, 동절기 와 하절기의 PAHs 농도 차이는 3 개 도시와 배경지역 모두에서 공통적으로 나타났지만, 지역적으로 측정한 달에 따른 PAHs농도 변화는 일정한 경향을 나타내지 않았다. 이러한 지역적 결과에 기초할 때, 어떤 특정 지역의 PAHs 오염도 특성을 이용하여 다른 도시의 $\mathrm{PAHs}$ 관리 대책을 수립하는 것은 합리적이지 않다는 것을 의미한다. 따라서, 대기 중 PAHs 오염에 대한 관 리 대책을 효율적으로 수립하기 위해서는 해당 지역 의 PAHs 오염도 특성에 대한 연구가 우선적으로 수 행되어야 할 것이다.

Fig. 4-6은 각각 서울시, 인천시 및 배경지역에서 측정된 7가지 개인 PAHs의 평균농도에 대한 계절별 변화 추이를 나타낸다. 총 PAHs 농도와 마찬가지로 서울시의 주거 및 도로변 지역 모두에서, 7 가지 PAHs 모두 겨울철 농도가 여름철 농도보다 높게 나타났다 (Fig. 4). 그러나, 도로변 지역에서는 7가지 PAHs 모 두 여름철 농도가 가장 낮게 나타난 반면에, 주거 지역 의 경우, PAHs의 종류에 따라 다른 계절적 농도 차이 를 나타내었다. 예를 들면, 서울시의 주거 지역에서 $\mathrm{BkF}$ 와 $\mathrm{BaP}$ 의 여름 농도가 겨울 다음으로 높은 농도 를 나타내었고, 다른 5 가지 PAHs의 여름 농도는 4계 절 중 가장 낮게 나타났다. 따라서, 주거 지역의 경우, $\mathrm{PAHs}$ 종류에 따란 계절적인 배출원이 다른 것으로 추정된다.

서울시와 유사하게, 인천시의 경우에 주거 및 도로 변 지역 모두에서, 7 가지 PAHs 모두 겨울철 농도가 여름철 농도보다 높게 나타났고(Fig. 5). 또한, 도로변 지역에서 7가지 PAHs 모두 여름철 농도가 가장 낮게 나타난 반면에, 도로변 지역의 경우, $\mathrm{BaP}$ 의 여름 농도 가 겨울 다음으로 높은 농도를 나타나, 서울시 주거지 역의 경향과 유사한 것으로 나타났고, 나머지 5 가지 


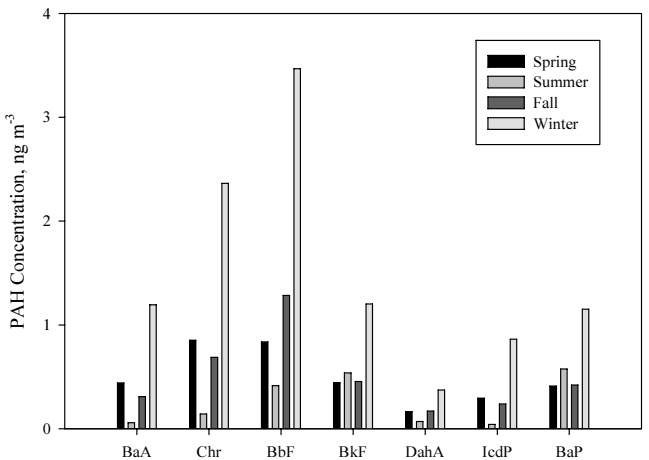

(a)

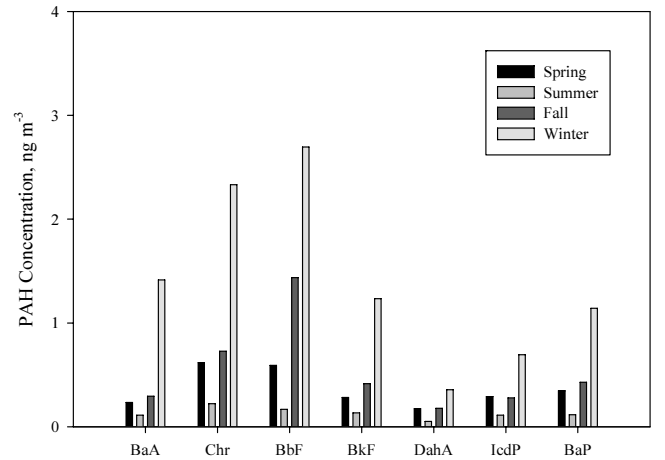

(b)

Fig. 4. Seasonal variation of individual PAH concentrations in Seoul, between January 1, 2006 and December, 31, 2008: (a) Dogokdong (residential site) and (b) Seoul station (roadside site).

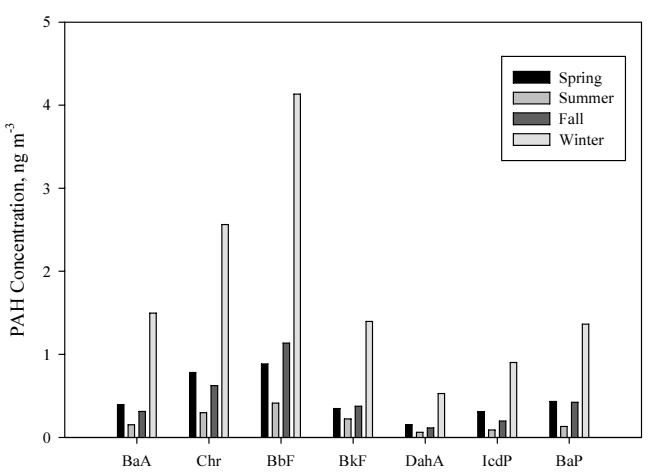

(a)

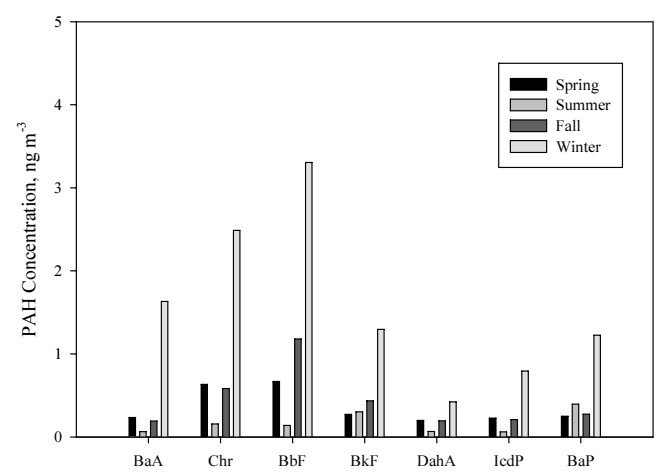

(b)

Fig. 5. Seasonal variation of individual PAH concentrations in Incheon, between January 1, 2006 and December, 31, 2008: (a) Sungeeidong (residential site) and (b) Yeonheedong (roadside site).

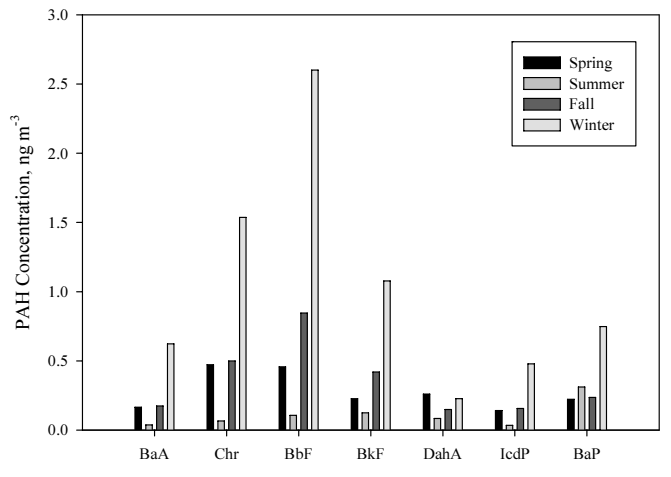

Fig. 6. Seasonal variation of individual PAH concentrations in a background area(Seokmolee), between January 1, 2006 and December, 31, 2008.
PAHs의 여름 농도는 4계절 중 가장 낮게 나타났다. 배경지역인 석모리의 경우에도, 7 가지 PAHs 모두에 대해 겨울철 농도가 가장 높게 나타났지만, Bap만이 여름철 농도가 봄과 가을철 농도보다 높게 나타나 (Fig. 6), 이들 지역의 대기 중 Bap는 다른 PAHs 종류 와는 다른 배출 특성을 가지는 것으로 이해된다.

7가지 개인 PAHs에 대하여 서울시와 인천시의 주 거 및 도로변 지역 그리고 배경 지역인 석모리에서 측 정된 농도를 통계적으로 분석한 결과를 Table 1 에 제 시하였다. 7 가지 PAHs 모두에 대하여 서울시와 인천 시가 배경 지역 보다 높은 것으로 나타났다. 서울시의 주거 지역 평균농도가 PAHs 종류에 따라 최소 0.19 $\mathrm{ng} / \mathrm{m}^{3}(\mathrm{DahA})$, 최대 $1.50 \mathrm{ng} / \mathrm{m}^{3}(\mathrm{BbF})$ 그리고 도로변 
Table 1. Statistics of PAH concentrations ( $\mathrm{ng} \mathrm{m}^{-3}$ ) measured in residential (Res) and roadside (Road) areas of Seoul and Incheon, and a background area (Seokmolee)

\begin{tabular}{|c|c|c|c|c|c|c|}
\hline \multirow{2}{*}{\multicolumn{2}{|c|}{ PAMs }} & \multicolumn{2}{|c|}{ Residential area } & \multicolumn{2}{|c|}{ Road side area } & \multirow{2}{*}{$\begin{array}{l}\text { Background } \\
\text { Seokmolee }\end{array}$} \\
\hline & & Seoul & Incheon & Seoul & Incheon & \\
\hline \multirow{4}{*}{$\mathrm{BaA}$} & Mean & 0.50 & 0.59 & 0.51 & 0.53 & 0.25 \\
\hline & $\mathrm{SD}^{*}$ & 0.02 & 0.03 & 0.03 & 0.02 & 0.01 \\
\hline & Min & $<\mathrm{mdl}$ & $<\mathrm{mdl}$ & $<\mathrm{mdl}$ & $<\mathrm{mdl}$ & $<\mathrm{mdl}$ \\
\hline & Max & 3.46 & 4.79 & 5.07 & 3.41 & 1.10 \\
\hline \multirow{4}{*}{ Chr } & Mean & 1.01 & 1.07 & 0.98 & 0.97 & 0.64 \\
\hline & $\mathrm{SD}$ & 0.03 & 0.04 & 0.03 & 0.03 & 0.02 \\
\hline & Min & $<$ mdl & $<$ mdl & 0.09 & 0.05 & $<$ mdl \\
\hline & Max & 5.36 & 7.06 & 6.57 & 5.15 & 2.55 \\
\hline \multirow{4}{*}{$\mathrm{BbF}$} & Mean & 1.50 & 1.64 & 1.22 & 1.32 & 1.00 \\
\hline & SD & 0.07 & 0.07 & 0.05 & 0.05 & 0.06 \\
\hline & Min & $<$ mdl & $<$ mdl & 0.03 & $<\mathrm{mdl}$ & $<$ mdl \\
\hline & Max & 11.8 & 11.7 & 7.38 & 7.26 & 8.80 \\
\hline \multirow{4}{*}{$\mathrm{BkF}$} & Mean & 0.66 & 0.59 & 0.52 & 0.58 & 0.46 \\
\hline & SD & 0.02 & 0.03 & 0.02 & 0.02 & 0.02 \\
\hline & Min & $<$ mdl & $<\mathrm{mdl}$ & $<\mathrm{mdl}$ & $<\mathrm{mdl}$ & $<\mathrm{mdl}$ \\
\hline & Max & 3.44 & 4.69 & 4.16 & 2.80 & 2.31 \\
\hline \multirow{4}{*}{ DahA } & Mean & 0.19 & 0.21 & 0.19 & 0.22 & 0.18 \\
\hline & SD & 0.01 & 0.01 & 0.01 & 0.01 & 0.01 \\
\hline & Min & $<\mathrm{mdl}$ & $<$ mdl & $<\mathrm{mdl}$ & $<\mathrm{mdl}$ & $<$ mdl \\
\hline & Max & 0.89 & 2.16 & 1.49 & 1.20 & 1.29 \\
\hline \multirow{4}{*}{ IcdP } & Mean & 0.36 & 0.38 & 0.34 & 0.32 & 0.20 \\
\hline & SD & 0.01 & 0.02 & 0.01 & 0.01 & 0.01 \\
\hline & Min & $<\mathrm{mdl}$ & $<$ mdl & $<\mathrm{mdl}$ & $<\mathrm{mdl}$ & $<\mathrm{mdl}$ \\
\hline & Max & 2.33 & 2.32 & 1.99 & 1.63 & 1.74 \\
\hline \multirow{4}{*}{$\mathrm{BaP}$} & Mean & 0.64 & 0.59 & 0.51 & 0.54 & 0.38 \\
\hline & SD & 0.03 & 0.02 & 0.02 & 0.02 & 0.01 \\
\hline & Min & $<\mathrm{mdl}$ & $<$ mdl & $<\mathrm{mdl}$ & $<\mathrm{mdl}$ & $<\mathrm{mdl}$ \\
\hline & Max & 4.40 & 4.14 & 4.25 & 2.63 & 1.99 \\
\hline
\end{tabular}

${ }^{*} \mathrm{SD}$ represents standard deviation.

지역 평균농도는 PAHs 종류에 따라 최소 0.19 $\mathrm{ng} / \mathrm{m}^{3}(\mathrm{DahA})$, 최대 $1.22 \mathrm{ng} / \mathrm{m}^{3}(\mathrm{BbF})$ 이고, 인천시의 주거 지역 평균농도가 PAHs 종류에 따라 최소 0.21 $\mathrm{ng} / \mathrm{m}^{3}(\mathrm{DahA})$, 최대 $1.64 \mathrm{ng} / \mathrm{m}^{3}(\mathrm{BbF})$ 그리고 도로변 지역 평균농도는 $\mathrm{PAHs}$ 종류에 따라 최소 0.22 $\mathrm{ng} / \mathrm{m}^{3}(\mathrm{DahA})$, 최대 $1.32 \mathrm{ng} / \mathrm{m}^{3}(\mathrm{BbF})$ 로 나타났다. 반 면에, 평균농도가 $\mathrm{PAHs}$ 종류에 따라 최소 0.18 $\mathrm{ng} / \mathrm{m}^{3}(\mathrm{DahA})$ 과 최대 $1.00 \mathrm{ng} / \mathrm{m}^{3}(\mathrm{BbF})$ 로 나타났다. 4 가지 $\mathrm{PAHs}(\mathrm{BaA}, \mathrm{BbF}, \mathrm{BkF}, \mathrm{DahA})$ 의 경우, 주거 지 역과 도로변 지역 모두에서 서울시 보다 인천시에서 높게 나타났다. $\mathrm{Chr}$ 의 경우, 주거 지역 및 도로변 지역 에서 서울시와 인천시가 유사하게 나타났고, IcdP는 주거 지역에서는 인천시가 높고 도로변 지역에서는
서울시가 다소 높게 나타났다. 반대로, $\mathrm{BaP}$ 는 주거 지 역에서는 서울시가 높고 도로변 지역에서는 인천시가 다소 높게 나타났다. 따라서, PAHs 종류에 따라 지역 별 농도 차이가 다르게 나타나고 이들 PAHs의 독성 세기도 종류에 따라 다르기 때문에 총 PAHs 농도 뿐 만 아니라 개인 PAHs 농도 특성도 고려하여 지역별 로 차등을 두는 PAHs 관리 대책 수립이 요구된다.

본 연구와 비슷한 시기에 다른 연구자들(박 등, 2006)이 서울시의 다른 주거지역에서 측정한 PAHs 농도를 본 연구의 서울시 농도와 비교하였다. 다섯 가 지 $\mathrm{PAHs}(\mathrm{BaA}, \mathrm{Chr}, \mathrm{BkF}, \mathrm{IcdP}, \mathrm{BaP})$ 평균농도의 경 우, 박 등(2006)은 각각 $0.66,1.18,1.08,0.58$ 및 0.72 $\mathrm{ng} / \mathrm{m}^{3}$ 로 보고하여 본 연구의 주거 지역 및 도로변 지 
역 결과 보다 다소 높았다. 그러나, 선행연구의 서울시 $\mathrm{BbF}$ 평균 농도 $\left(1.31 \mathrm{ng} / \mathrm{m}^{3}\right)$ 는 본 연구의 주거 지역 평 균농도 $\left(1.50 \mathrm{ng} / \mathrm{m}^{3}\right)$ 보다는 낮게 나타났고, 도로변 지 역 평균농도 $\left(1.22 \mathrm{ng} / \mathrm{m}^{3}\right)$ 보다는 높게 나타났으며, 선 행연구의 $\mathrm{DahA}$ 의 평균농도 $\left(0.10 \mathrm{ng} / \mathrm{m}^{3}\right)$ 는 본 연구의 주거 지역 $\left(0.19 \mathrm{ng} / \mathrm{m}^{3}\right)$ 과 도로변 지역 $\left(0.19 \mathrm{ng} / \mathrm{m}^{3}\right)$ 의 평균 농도보다 낮게 나타났다. 한편, 본 연구 결과를 외국 도시와 비교할 때에도 PAHs 종류에 따라 다른 차이를 나타내었다. 예를 들면, $\mathrm{Hu}$ 등(2007)이 중국 텐진의 도로변 지역에서 측정한 $\mathrm{BbF}$ 농도 $\left(1.5 \mathrm{ng} / \mathrm{m}^{3}\right)$ 와는 본 연구 결과가 유사하게 나타났지만, $\mathrm{BaA}(0.8$ $\left.\mathrm{ng} / \mathrm{m}^{3}\right), \operatorname{Chr}\left(2.0 \mathrm{ng} / \mathrm{m}^{3}\right), \operatorname{BbF}\left(1.5 \mathrm{ng} / \mathrm{m}^{3}\right)$ 및 $\mathrm{BaP}(1.3$ $\mathrm{ng} / \mathrm{m}^{3}$ ) 보다는 본 연구 결과가 낮게 나타났다. 또한, Andreou와 Rapsomanikis(2009)가 그리스 아테네의 도로변 지역에서 측정한 $\mathrm{Chr}$ 농도 $\left(0.95 \mathrm{ng} / \mathrm{m}^{3}\right)$ 와 본 연구 결과가 유사하게 나타났으나, $\operatorname{BbF}\left(9.5 \mathrm{ng} / \mathrm{m}^{3}\right)$, $\operatorname{BkF}\left(2.9 \mathrm{ng} / \mathrm{m}^{3}\right), \operatorname{IcdP}\left(2.1 \mathrm{ng} / \mathrm{m}^{3}\right)$ 그리고 $\operatorname{Bap}(2.1$ $\mathrm{ng} / \mathrm{m}^{3}$ ) 농도 보다는 본 연구 결과가 훨씬 낮게 나타났 다.

\section{2. $\mathrm{PCA}$ 를 이용한 주거 및 도로변 지역의 발생원 추정}

$\mathrm{PAHs}$ 측정 자료에 $\mathrm{PCA}$ 통계분석기법을 적용하여 주거지역과 도로변 지역의 대기 중 PAHs에 대한 발 생원을 추정하였다. 구체적인 오염원 정보(profile)가 필수적으로 요구되는 화학적 물질수지(chemical mass balance, CMB) 모델과 비교하여 PCA 모델은 이러한 오염원 정보가 없어도 잠재적인 오염원을 예측할 수 있다는 장점이 있다. 반면에, PCA는 자료의 자유도, 즉 시료의 수가 가능한 한 많은 경우에만 적절하게 활 용될 수 있다는 한계성이 있다(Song 등, 2008). 따라 서, 본 연구는 측정된 7가지 PAHs에 대한 자유도를 증가시키기 위하여 지역 범주를 주거 및 도로변 지역 으로 구분하여 서울시와 인천시를 병합하여 PCA 모 델을 활용하였다. PCA 분석 결과로서, 선행연구 (Jollife, 2002; Lucarelli 등, 2004)에서 이용된 바와 같이, 주성분 점수가 0.5 이상이고 eigenvalue가 1 이 상인 인자를 주성분으로 인정하여 주거 지역과 도로 변 지역 각각에 대하여 PCA 주성분만을 Table 2에 제 시하였다. 주거 지역의 경우, 7 가지 PAHs 모두의 주 성분 점수가 0.5 이상으로 나타났고, 도로변 지역에서
Table 2. Results of PCA in residential and roadside areas

\begin{tabular}{ccc}
\hline \multirow{2}{*}{ Variables } & Residential area & Roadside area \\
\cline { 2 - 3 } & Primary factor & Primary factor \\
\hline \hline BaA & 0.714 & 0.887 \\
Chr & 0.957 & 0.969 \\
BbF & 0.769 & 0.717 \\
BkF & 0.903 & 0.935 \\
DahA & 0.570 & 0.462 \\
IcdP & 0.894 & 0.904 \\
BaP & 0.871 & 0.921 \\
EIGENVALUE & 4.714 & 4.991 \\
Probability, $\%$ & $67.35 \%$ & $71.30 \%$ \\
Cuulative & $67.35 \%$ & $71.30 \%$ \\
value, $\%$ & & \\
\hline
\end{tabular}

는 DahA의 주성분 점수(0.462)만이 0.5 보다 약간 낮 게 나타났다. 주거 지역과 도로변 지역에서 주인자가 모두 약 $70 \%$ 정도를 대변하는 것으로 나타났다. Esen 등(2008)과 Ravindra 등(2008)은 $\mathrm{BbF}, \mathrm{BkF}, \mathrm{BaP}$ 가 휘발 유 차량 배출과 관련이 있고, Kulkarni와 Venkataraman (2000)과 Ho 등(2002)은 $\mathrm{Chr}$ 이 휘발유 차량 배출가스 와 관련이 있는 것으로 보고하였다. 또한, Esen 등 (2008)은 $\mathrm{BaA}$ 와 $\mathrm{Chr}$ 은 디젤 차량 배출가스와 관련이 있는 것으로 보고하였다. 반면에, Ravindra 등(2008) 은 $\mathrm{BbF}$ 와 $\mathrm{BkF}$ 가 디젤 차량 배출가스와 관련이 있고, Dong과 Lee(2009)는 Bap와 BkF가 전체 차량의 배출 가스와 관련이 있는 것으로 보고하였다. 나아가, Esen 등(2008)은 $\mathrm{BaA}$ 와 $\mathrm{Chr}$ 이 석탄 연소와 관련이 있고, Kulkarni와 Venkataraman(2000)은 $\mathrm{BaP}$ 가 목재 소각 및 취사를 위한 연료 사용과 밀접한 관련이 있는 것으 로 보고하였다. Yang 등(1998)은 $\mathrm{BaA}$ 와 $\mathrm{BaP}$ 가 산업체 배출가스와 관련이 있으며, Kulkarni와 Venkataraman (2000)은 $\mathrm{BbF}$ 가 오일 연소 그리고 $\mathrm{Chr}$ 이 소각로 배출 가스와 관련이 있는 것으로 보고하였다. 결과적으로, 본 연구의 주거 및 도로변 지역에서 측정된 PAHs는 휘발유 차량, 디젤 차량, 소각로, 취사 연료 사용 중 특 정 오염원의 영향을 개별적으로 구분하기는 쉽지 않 으며, 이들 연소 관련 오염원 모두가 복합적으로 작용 한 결과로 유추된다. 


\section{4. 결 론}

본 연구는 국내 주요 2 개 도시와 1 개 배경지역에서 위해도가 높은 대기 중 입자 형태 PAHs의 시간적 및 공간적 농도 특성을 분석하고, 다 변량 통계기법인 $\mathrm{PCA}$ 를 활용하여 $\mathrm{PAHs}$ 의 발생원을 정성적으로 평가 하였다. 주거 지역과 도로변 지역 또는 도시 종류와 배 경지역과 관계없이, 모든 조사 지역에서 총 PAHs 농 도가 하절기에 비해 동절기에 총 $\mathrm{PAHs}$ 농도가 높게 나타나, 동절기의 난방 연료 사용과 추운 날씨로 인한 연료의 불완전 연소로 인해 동절기에 총 $\mathrm{PAHs}$ 농도 가 높게 나타난 것으로 판단되었다. 그러나, 개인별 $\mathrm{PAHs}$ 의 경우 지역에 따라 오염도가 다르고, 지역별 로 개인 PAHs 오염도 경향도 다르게 나타났다. 서울 시의 주거 지역 평균농도는 PAHs 종류에 따라 최소 $0.19 \mathrm{ng} / \mathrm{m}^{3}(\mathrm{DahA})$, 최대 $1.50 \mathrm{ng} / \mathrm{m}^{3}(\mathrm{BbF})$ 그리고 도 로변 지역 평균농도는 $\mathrm{PAHs}$ 종류에 따라 최소 0.19 $\mathrm{ng} / \mathrm{m}^{3}(\mathrm{DahA})$, 최대 $1.22 \mathrm{ng} / \mathrm{m}^{3}(\mathrm{BbF})$ 이고, 인천시의 주거 지역 평균농도가 $\mathrm{PAHs}$ 종류에 따라 최소 0.21 $\mathrm{ng} / \mathrm{m}^{3}(\mathrm{DahA})$, 최대 $1.64 \mathrm{ng} / \mathrm{m}^{3}(\mathrm{BbF})$ 그리고 도로변 지역 평균농도는 $\mathrm{PAHs}$ 종류에 따라 최소 0.22 $\mathrm{ng} / \mathrm{m}^{3}(\mathrm{DahA})$, 최대 $1.32 \mathrm{ng} / \mathrm{m}^{3}(\mathrm{BbF})$ 로 나타났다. 반 면에, 평균농도가 $\mathrm{PAHs}$ 종류에 따라 최소 0.18 $\mathrm{ng} / \mathrm{m}^{3}(\mathrm{DahA})$ 과 최대 $1.00 \mathrm{ng} / \mathrm{m}^{3}(\mathrm{BbF})$ 로 나타났다. 따라서, 대기 중 PAHs를 효율적으로 관리하기 위해 서는 지역 특성이 고려되어야 하는 것으로 결론된다. PCA 결과에 기초할 때, 본 연구의 주거 및 도로변 지 역에서 측정된 PAHs는 휘발유 차량, 디젤 차량, 소각 로, 취사 연료 사용 중 특정 오염원의 영향을 개별적으 로 구분하기는 쉽지 않으며, 단지 이들 연소 관련 오염 원 모두가 복합적으로 작용한 결과로 유추되었다. 이 러한 연구의 한계성을 극복하기 위하여 보다 많은 자 료를 활용한 PAHs 오염원의 정성적 분석 뿐만 아니 라 정량적 분석 연구가 필요할 것이다.

\section{감사의 글}

이 논문은 2009년도 경북대학교 학술연구비에 의 하여 연구되었습니다.
참 고 문 헌

김형섭, 김영성, 김종국, 2006, 2002년 6월부터 11 월까지 전주지역 대기 중 다환 방향족 탄화수소의 특성, 한 국대기환경학회지, 22, 499-508.

박찬구, 윤중섭, 어수미, 신정식, 김민영, 손종열, 모세영, 2006, 서울지역 대기 중 다환방향족탄화수소의 발 생원별 기여도 평가, 한국대기환경학회지, 22, 287-295.

이지이, 김용표, 배귀남, 박수미, 진현철, 2008 , 서울시 도 로변에서 입자상 다환방향족탄화수소의 농도 특성, 한국대기환경학회지, 24, 133-142.

한진석, 이민도, 임용재, 이상욱, 김영미, 공부주, 안준영, 홍유덕, 2006, 수도권지역에서 환경대기 중 유해대 기오염물질(VOCs, aldehydes, PAHs) 농도분포 특 성 연구, 한국대기환경학회지, 22, 574-589.

Andreou, G., Rapsomanikis, G., 2009, Polycyclic aromatic hydrocarbons and their oxygenated derivatives in the urban atmospheric of Athens, J. Hazard. Mater., 172, 363-373.

Amodio, M., Bruno, P., Caselli, M., de Gennaro, G., Dambruoso, P. R., Daresta, B. E., Ielpo, P., Gungol, F., Placentino, C. M., Paolillo, V., Tutino, M., 2008, Chemical characterization of fine particulate matter during peak PM10 episodes in Apulia (South Italy), Atmos. Res., 90, 313-325.

Bi, X., Simoneit, B. R. T., Sheng, G., Fu, J., 2008, Characterization of molecular markers in smoke from residential coal combustion in China, Fuel, 87, 112-119.

Bruno, P., Caselli, M., de Gennaro, G., de Rienzo, M., Ielpo, P., Manigrassi, D., 2002, Collection and analytical characterization of atmospheric particulate in the city of Bari, Annali di Chimica., 92, 815-824.

Chang, K. F., Fang, G. C., Chen, J. C., Wu, Y. S., 2006, Atmospheric polycyclic aromatic hydrocarbons (PAHs) in Asia: A review from 1999 to 2004, Environ. Poll., 142, 388-396.

Dong, T. T., Lee, B. K., 2009, Characteristics, toxicity, and source apportionment of polycyclic aromatic hydrocarbons (PAHs) in road dust of Ulsan, Korea, Chemosphere, 74, 1245-1253.

Esen, F., Tasdemir, Y., Vardar, N., 2008, Atmospheric concentrations of PAHs, their possible sources and gas-to-particle portioning at a residential site of Bursa, Turkey, Atmos. Res., 88, 243-255. 
Garban, B., Blanchoud, H., Motelay-Massei, A., Chevreuil, M., Ollivon, D., 2002, Atmospheric bulk deposition of PAHs onto France: trends from urban to remote sites, Atmos. Environ. 36, 5395-5403.

Guo, H., Wang, T., Louie, P. K. K., 2004, Source apportionment of ambient non methane hydrocarbons in Hong Kong: application of principal component analysis/absolute principal component scores (PCA/ APCS) receptor model, Environ. Poll., 129, 489-498.

Guo, H., So, K. L., Simpson, I. J., Barletta, B., Meinardi, S., Blake, D. R., 2007, $\mathrm{C}_{1}-\mathrm{C}_{8}$ volatile organic compounds in the atmosphere of Hong Kong: Overview of atmospheric processing and source apportionment, Atmos. Environ., 41, 1456-1472.

Halsall, C. J., Sweetman, A. J., Barrie, L. A., Jones, K. C., 2001, Modelling the behaviour of PAHs during atmospheric transport from the UK to the Arctic, Atmos. Environ., 35, 255-267.

Ho, K. F., Lee, S. C., Chiu, G. M. Y., 2002, Characterization of selected volatile organic compounds, polycyclic aromatic hydrocarbons and carbonyl compounds at a roadside monitoring station, Atmos. Environ., 36, 57-65.

Hu, Y., Bai, Z., Zhang, L., Wang, X., Zhang, L., Yu, Q., Zhu, T., 2007, Health risk assessment for traffic policemen exposed to polycyclic aromatic hydrocarbons (PAHs) in Tianjin, China, Sci. Total Environ., 382, 240-250.

Jolliffe, I. T., 2002, Principal Component Analysis, 2nd Ed., Springer, New York.

Kameda, Y., Shirai, J., Komai, T., Nakanishi, J., Masunaga, S., 2005, Atmospheric polycyclic aromatic hydrocarbons: size distribution, estimation of their risk and their depositions to human respiratory tract, Sci. Total Environ., 340, 71-80.

Kulkarni, P., Venkataraman, C., 2000, Atmospheric polycyclic aromatic hydrocarbons in Mumbai, India, Atmos. Environ., 34, 2785-2790.

Li, J., Zhang, G., Li, X. D., Qi, S. H., Liu, G. Q., Peng, X. Z., 2006, Source seasonality of polycyclic aromatic hydrocarbons (PAHs) in a subtropical city, Guangzhou, South China, Sci. Total Environ., 355, 145-155.
Liu, M., Cheng, S. B., Ou, D. N., Hou, L. J., Gao, L., Wang, L. L., Xie, Y. S., Yang, Y., Xu, S. Y., 2007, Characterization, identification of road dust PAHs in central Shanghai areas, China, Atmos. Environ., 41, 8785-8795.

Lucarelli, F., Mandò, A., Nava, S., Prati, P., Zucchiatti, A., 2004, One-year study of the elemental composition and source apportionment of $\mathrm{PM}_{10}$ aerosols in Florence, Italy, J. Air Waste Manage. Assoc., 54, 1372-1382.

Mastral, A. M., López, J. M., Callén, M. S., García, T., Murillo, R., Navarro, M. V., 2003, Spatial and temporal PAH concentrations in Zaragoza, Spain, Sci. Total Environ., 307, 111-124.

Ravindra, K., Sokhi, R., Grieken, R. V., 2008, Atmospheric polycyclic aromatic hydrocarbons: source attribution, emission factors and regulation, Atmos. Environ., 42, 2895-2921.

Simoneit, B. R. T., Medeiros, P. M., 2005, Combustion products of plastics as indicators for refuse burning in the atmosphere, Environ. Sci. Technol., 39, 6961-6970.

Song, Y., Dai, W., Shao, M., Liu, Y., Lu, S., Kuster, W., Goldan, P., 2008, Comparison of receptor models for source apportionment of volatile organic compounds in Beijing, China, Environ. Poll., 156, 174-183.

USEPA(United States of Environmental protection Agency), 2003, Appendix A to 40 CFR. Part 423-126 Priority Pollutants. 2003. Available from: http://www.epa.gov/region01/npdes/permits/generic /prioritypollutants.pdf.

Vione, D., Barra, S., de Gennaro, G., de Rienzo, M., Pozzoli, L., Gilardoni, S., Perrone, M. G., 2004, Polycyclic aromatic hydrocarbons in the atmosphere: monitoring, sources, sinks and fate II: sinks and fate, Annali di chimica., 94, 257-268.

Yang, H. H., Lee, W. J., Chen, S. J., Lai, S. O., 1998, PAH emission from various industrial stacks, J. Hazard. Mater., 60, 159-174.

Zielinska, B., Sagebiel, J., McDonald, J. D., Whitney, K., Lawson, D. R., 2004, Emission rates and comparative chemical composition from selected in-use diesel and gasoline-fueled vehicles, Air Waste Manag. Assoc., 54, 1138-1150. 